\title{
Modelagem Empírica da Transferência Goticular Projetada em Processos de Soldagem GMAW
}

\author{
(Empirical Modeling of Projected Spray Transfer in GMAW Processes)
}

\author{
Jesús Emilio Pinto Lopera ${ }^{1}$, Sadek C. Absi Alfaro ${ }^{1}$, José Mauricio S. T. Motta \\ ${ }^{1}$ Universidade de Brasilia, Departamento de Engenharia Mecânica,Brasília,DF, Brasil, jesusemilio@unb.br; sadek@unb.br, \\ jmmotta@unb.br
}

\begin{abstract}
Resumo
Este trabalho apresenta uma metodologia para modelar empiricamente o modo de transferência goticular projetada em processos de soldagem GMAW utilizando algoritmos de processamento de imagens digitais e a metodologia de superfície de resposta. Modelos correspondentes ao tamanho e à frequência de destacamento das gotas são obtidos em relação às entradas de tensão e velocidade de alimentação do arame. Os dados experimentais de tamanho e frequência de destacamento das gotas, com os quais foram desenvolvidos os modelos, foram calculados a partir de imagens de transferência metálica adquiridas com uma câmera de alta velocidade e a técnica de iluminação conhecida como perfilografia. As técnicas utilizadas na coleta dos dados e os modelos encontrados validaram a metodologia proposta por apresentar uma correta representação do modo de transferência. O empescoçamento produzido pelo efeito pinch se apresentou como um parâmetro adequado para rastrear a formação das gotas e calcular a sua frequência de destacamento.
\end{abstract}

Palavras-chave: Transferência goticular; GMAW; modelagem empírica; metodologia de superfície de resposta; processamento de imagens digitais.

\begin{abstract}
This paper presents a methodology to get empirical models of projected spray transfer mode in GMAW processes. Digital image processing algorithms were used together with the surface response methodology. Droplet size and transfer rate models were obtained in relation to voltage and wire feed rate. To develop the models, experimental data collection of droplet size and transfer rate were calculated from metal transfer images acquired with a high-speed camera and backlighting illumination. The techniques for data collecting and the models constructed validated the proposed methodology presenting a correct transfer mode representation. The "neck-shrink" produced by the pinch effect proved to be an appropriate parameter to track and for calculating the droplets transfer rate.
\end{abstract}

Key-words: Spray transfer; GMAW; empirical modeling; response surface methodology; digital images processing.

\section{Introdução}

O processo de soldagem GMAW (Gas Metal Arc Welding), baseado num arame-eletrodo nu consumível, alimentado continuamente, é referenciado como um dos processos mais utilizados na produção industrial devido a sua facilidade de automação, sua grande produtividade e a qualidade de suas soldas. Uma alternativa aos arames maciços em processos GMAW é o uso de arames com enchimento com ligas metálicas. Estes são denominados arames tubulares ou, mais comumente, pelo termo em inglês metal-cored (MC). Os arames MC têm a função básica de adição de elementos de liga através da alma, embora muitos arames tubulares comerciais exerçam também uma ação secundaria metalúrgica. Como explicam Scotti e Ponomarev [1], os arames tubulares são diferentes aos eletrodos tubulares (flux-cored) uti-

(Recebido em 06/03/2012; Texto final em 08/07/2012). lizados nos processos FCAW (Flux Cored Arc Welding). Lyttle [2] expõe as vantagens que tem os arames MC sobre os arames maciços e manifesta a importância dos mesmos nas demandas do mercado em processos GMAW.

Atualmente ao redor do mundo realizam-se uma grande variedade de projetos de pesquisa enfocados no controle de processos de soldagem. Neste sentido, os sistemas de controle precisam de modelos matemáticos que, dependendo dos parâmetros de entrada no sistema e as resposta desejadas pelos usuários, indiquem ao sistema o rumo a seguir em determinado instante de tempo. No caso dos processos GMAW, uma das linhas de pesquisa mais interessantes é o controle da quantidade de material depositado nos cordões de solda, na qual o tempo de formação e o tamanho atingido pelas gotas são de grande importância. No caso particular desta pesquisa foram analisados e modelados o tamanho e a frequência de destacamento das gotas na transferência goticular projetada em um processo GMAW com um arame de tipo metal-cored. Os modelos visam atingir de forma pratica as necessidades de futuros sistemas que permitam controlar a quantidade de material depositado nas soldas. 
A construção dos modelos pode ser feita utilizando uma abordagem teórica de análise, como no caso da Teoria do Balanço Estático de Forças e a Teoria da Instabilidade Pinch, ou podem ser modelos empíricos determinados a partir da análise estática de diferentes experimentos. As complexas correlações que existem entre os fatores que governam a transferência metálica e sua influência nas respostas fazem com que os modelos teóricos sejam limitados a poucos parâmetros, o que indica que estudos experimentais ainda são importantes. Os modelos empíricos são obtidos através do estudo experimental dos parâmetros adotados e seus efeitos. Entre as técnicas de estudo mais utilizadas para estabelecer modelos empíricos em processos de soldagem encontram-se os experimentos fatoriais, usados, por exemplo, por Subramaniam et al. [3] e Praveen, Kang e Prasad [4], para identificar parâmetros de trabalho em GMAW-P, a regressão linear, usada por Murray [5] para encontrar correlação entre fatores de entrada e respostas nos processos GMAW, e a metodologia de superficie de resposta (MSR), usada por Correia et al. [6], para otimizar fatores de entrada com relação a características do cordão de solda. Benyounis e Olabi [7] comparam estas e outras técnicas de estudo, como redes neurais, em diferentes processos de soldagem e destacam o interesse na adaptação de modelos baseados em MSR e o potencial que estes têm na otimização de parâmetros que consigam gerar processos de soldagem seguros, econômicos, de boa aparência e boa qualidade.

Assim, o objetivo deste trabalho é utilizar a metodologia de superfície de resposta para encontrar os modelos empíricos de tamanho e frequência de destacamento das gotas que representem a transferência goticular projetada. Metodologias de processamento de imagens digitais foram propostas para medir de forma automática o tamanho e a frequência de destacamento das gotas a partir da filmagem dos experimentos com uma câmera de alta velocidade e a técnica conhecida como perfilografia. No caso da medição da frequência de destacamento, trabalhos como Maia [8] se baseiam em uma região (janela) pela qual passa uma gota em transferência e assim é registrada (contada); a resposta desse mecanismo tem bons resultados e é mais rápida que a apresentada neste trabalho. A dificuldade desta técnica é que o quantificador depende de um segmento específico da imagem e conta tudo o que passe pela janela, assim, este pode ser suscetível ao ruído externo que pode vir da poça, do arame ou até de um possível respingo; por outro lado, se a mesma gota aparece em varias imagens e passa pela janela, a gota poderia ser contada mais de uma vez. Este problema pode ser solucionado diminuindo-se o tamanho da janela, mas para uma taxa de aquisição de imagens de 1000 quadros por segundo (a metade da usada por Maia [8] e a mesma deste trabalho) e para qualquer sequência de imagens independente dos parâmetros de solda não se pode garantir uma região livre de ruído tal que a gota passe por ela só uma vez e que todas as gotas destacadas sejam contadas. Por esse motivo, a metodologia proposta neste trabalho está baseada no seguimento da formação das gotas na ponta do arame, o qual permite identificar e contar o destacamento de cada gota durante o processo. A medição do tamanho de cada gota é feita pela contagem dos pixeis que as conformam e a robustez do algoritmo apresentado está na correta delimitação da gota.

\section{Transferência goticular projetada}

Os modos naturais de transferência metálica num processo de soldagem GMAW se apresentam em dois grupos: de curto circuito e de vôo livre. No segundo grupo encontra-se a transferência goticular projetada, conhecida em inglês como projected spray [9]. Este modo de transferência é importante nos setores industriais que envolvem processos de soldagem de chapas grossas devido a apresentar altas densidades de corrente e, com elas, altas temperaturas e penetração. A transferência ocorre basicamente com gases de proteção a base de argônio e com eletrodo positivo. Este modo de transferência é caracterizado pela passagem de pequenas gotas uniformes de forma sequencial, em alta frequência (na ordem de centenas por segundo) desde a ponta do arame até a peça a soldar. O IIW (International Institute of Welding) [10] definiu que, no modo de transferência goticular, o diâmetro das gotas é menor que 1,25 vezes o diâmetro do eletrodo.

Com o aumento da corrente no processo de soldagem o tamanho das gotas em transferência se reduz e a frequência de destacamento aumenta. Este comportamento é devido principalmente ao conhecido efeito pinch, o qual é produzido pelas forças de Lorentz ao redor do arame. Scotti e Ponomarev [1] descrevem que a densidade de corrente através do arame e do campo magnético ao redor do mesmo vão produzir forças radiais no sentido do centro do arame. Estas forças são as denominadas forças de Lorentz e quanto maior a corrente, maiores são as forças. Para um condutor sólido, o efeito destas forças pode ser desprezado, mas para um condutor líquido (como o caso da gota metálica), as forças de Lorentz deslocam a superfície para o centro do condutor. Desta forma, a gota tende a se alongar na direção oposta ao eletrodo, formando um empescoçamento da gota no acoplamento com o arame produzindo o efeito pinch. Com base neste conceito, no presente trabalho são feitas medidas do diâmetro da gota em formação e do pescoço para determinar o destacamento de cada gota, e assim, a frequência de destacamento do processo de transferência goticular.

\section{Metodologia de Superfície de Resposta}

A metodologia de superfície de resposta é um conjunto de técnicas estatísticas e matemáticas usadas para modelar processos nos quais as respostas sejam influenciadas por diferentes variáveis independentes (fatores de entrada). O modelo gerado permite estimar o valor da resposta do processo em função das variáveis de estudo dentro da região de trabalho. $\mathrm{O}$ gráfico obtido a partir do modelo em função das variáveis de entrada é a superfície de resposta, e permite inspecionar visualmente a resposta para certa região (valores) das variáveis de entrada.

Entre os planejamentos experimentais na MSR mais conhecidos encontra-se o Planejamento Composto Central (PCC), o qual está baseado em um planejamento fatorial completo mais um planejamento estrela com réplicas do ponto central e é usado em modelos de segunda ordem. Neste caso, os testes do planejamento fatorial são utilizados para a obtenção dos termos lineares e de interação, os testes do planejamento estrela fornecem os termos de segunda ordem e os testes replicados (no ponto central) fornecem uma estimativa do erro experimental. Na concepção 
dos modelos, as variáveis de entrada são codificadas de forma que as diferenças entre as unidades de medida das variáveis não influenciem as respostas do modelo. As variáveis de entrada são codificadas a partir da seguinte expressão:

$x_{j}=\frac{\hat{1}_{j}-\left(\max \left(\hat{1}_{j}\right)+\min \left(\hat{\mathrm{i}}_{j}\right) / 2\right.}{\left(\max \left(\hat{1}_{j}\right)-\min \left(\hat{\mathrm{i}}_{j}\right) / 2\right.}$

, onde $x_{j}$ indica a variável codificada e $\xi_{j}$ o valor real da variável de entrada, $j$ representa a variável de entrada; $\max \left(\xi_{j}\right)$ e $\min \left(\xi_{j}\right)$ são os valores reais do planejamento fatorial. Depois de definida a região de estudo, os valores dos níveis codificados e das variáveis de entrada são estabelecidos pelo PCC, mas as respostas do modelo inicial estão dadas em função dos níveis codificados, de forma que a Equação 1 seja utilizada para traduzir as respostas do modelo aos valores reais (modelo final).

Para estabelecer o modelo na metodologia de superfície de resposta, Myers, Montgomery e Anderson-Cook [11] fazem uso da técnica de regressão múltipla, na qual, para o caso de um modelo de segunda ordem, se tem a forma:

$y=\beta_{0}+\beta_{1} x_{1}+\beta_{2} x_{2}+\beta_{1} x_{1}^{2}+\beta_{2} x_{2}^{2}+\beta_{2} x_{1} x_{2}+\varepsilon$

, onde $y$ representa a resposta, $x$ a variável de entrada e $\varepsilon$ o desvio aleatório do modelo e assume-se que este tem uma distribuição normal com média zero e variância $\sigma^{2}$. Os termos $\beta$ representam os parâmetros que determinam o modelo e são chamados de coeficientes de regressão. Para determinar estes coeficientes, geralmente é utilizado o principio dos mínimos quadrados. Em geral, o planejamento experimental do PCC para um modelo de segunda ordem e duas variáveis de entrada é desenvolvido como se indica na Tabela 1.

Tabela 1. Planejamento experimental do PCC.

Onde: $y_{1}, y_{2}, \ldots, y_{12}$ são as respostas dos experimentos. Assim,

\begin{tabular}{|c|c|c|c|}
\hline \multirow{2}{*}{ Observação } & \multicolumn{2}{|c|}{ Variáveis codificadas } & \multirow{2}{*}{ Respostas } \\
\cline { 2 - 3 } & $x_{1}$ & $x_{2}$ & \\
\hline 1 & -1 & -1 & $y_{1}$ \\
\hline 2 & 1 & -1 & $y_{2}$ \\
\hline 3 & -1 & 1 & $y_{3}$ \\
\hline 4 & 1 & 1 & $y_{4}$ \\
\hline 5 & $-\sqrt{2}$ & 0 & $y_{5}$ \\
\hline 6 & $\sqrt{2}$ & 0 & $y_{6}$ \\
\hline 7 & 0 & $-\sqrt{2}$ & $y_{7}$ \\
\hline 8 & 0 & $\sqrt{2}$ & $y_{8}$ \\
\hline 9 & 0 & 0 & $y_{9}$ \\
\hline 10 & 0 & 0 & $y_{10}$ \\
\hline 11 & 0 & 0 & $y_{11}$ \\
\hline 12 & 0 & 0 & $y_{12}$ \\
\hline
\end{tabular}

para encontrar os valores dos coeficientes de regressão se utiliza a Tabela 1 nas seguintes expressões:

$\boldsymbol{y}=\left[\begin{array}{c}y_{1} \\ y_{2} \\ \vdots \\ y_{n}\end{array}\right]$

$$
\mathbf{X}=\left[\begin{array}{rrrrrr} 
& x_{1} & x_{2} & x_{1}^{2} & x_{2}^{2} & x_{1} x_{2} \\
1 & -1 & -1 & 1 & 1 & 1 \\
1 & 1 & -1 & 1 & 1 & -1 \\
1 & -1 & 1 & 1 & 1 & -1 \\
1 & 1 & 1 & 1 & 1 & 0 \\
1 & -\sqrt{2} & 0 & 2 & 0 & 0 \\
1 & \sqrt{2} & 0 & 2 & 0 & 0 \\
1 & 0 & -\sqrt{2} & 0 & 2 & 0 \\
1 & 0 & \sqrt{2} & 0 & 2 & 0 \\
1 & 0 & 0 & 0 & 0 & 0 \\
1 & 0 & 0 & 0 & 0 & 0 \\
1 & 0 & 0 & 0 & 0 & 0 \\
1 & 0 & 0 & 0 & 0 & 0
\end{array}\right]
$$

Onde os valores dos coeficientes são dados pelo vetor $\mathbf{b}$, da seguinte forma:

$\mathbf{b}=\left(\mathbf{X}^{T} \mathbf{X}\right)^{-1} \mathbf{X}^{T} \mathbf{y}$

, e os coeficientes são apresentados como: $\mathbf{b}=b_{0}, b_{1}, b_{2}, b_{3}, b_{4}, b_{5}$. Assim, para o caso do modelo de segunda ordem, este é expresso por uma equação matemática da seguinte forma:

$\hat{y}=b_{0}+b_{1} x_{1}+b_{2} x_{2}+b_{3} x_{1}^{2}+b_{4} x_{2}^{2}+b_{5} x_{1} x_{2}$

A variação apresentada pelo modelo com respeito aos valores medidos é dada pelo coeficiente de variação múltipla, dado por:

$R_{a d j}^{2}=1-\frac{n-1}{n-(k+1)} \frac{\sum_{i=1}^{n}\left(y_{i}-\hat{y}_{i}\right)^{2}}{\sum_{i=1}^{n}\left(y_{i}-\bar{y}\right)^{2}}$

Onde cada valor de $\hat{y}_{i}$ e dado pela equação do modelo avaliada nas variáveis de entrada utilizadas na resposta $y_{i}$. $\mathrm{O}$ valor $\bar{y}$ é a média amostral dos resultados experimentais.

\section{Planejamento Experimental}

De acordo com o planejamento composto central da metodologia de superfície de resposta, foram selecionados nove pontos de trabalho dentro da região de transferência goticular projetada. As respostas medidas e os fatores de entrada dos experimentos coincidiram com as respostas e as variáveis de entrada dos modelos. Por serem as respostas medidas dependentes de 
parâmetros como o tipo de gás de proteção ou composição e diâmetro do arame-eletrodo, neste trabalho os experimentos foram estabelecidos exclusivamente para variações de tensão e velocidade de arame, fatores de controle tradicionais de uma fonte de energia de tipo tensão constante. Os fatores de entrada restantes foram mantidos constantes durante os experimentos.

Deste modo, os parâmetros de trabalho constantes foram: distância bico de contato-peça (DBCP), 18 mm; vazão de gás de proteção, 14 litros/min (medida na saída do cilindro); velocidade de soldagem, $10 \mathrm{~mm} / \mathrm{s}$; ângulo de ataque reto. Os materiais utilizados foram: eletrodo do tipo arame tubular 410NiMo MC, com diâmetro de $1.2 \mathrm{~mm}$ (material disponível no laboratório para testes); material de base de aço 1020 em formato de chapa plana; gás de proteção a base de $\mathrm{Ar}$ e $25 \% \mathrm{CO}_{2}$; e fonte de soldagem Fronius Trans Puls Synergic 5000. Desta forma, observando as filmagens de transferência metálica obtidas em diferentes experimentos com diferentes parâmetros de entrada na fonte de soldagem, os limites da região de trabalho foram estabelecidos como:

- Intervalo de velocidade de alimentação de arame $\left(\xi_{1}\right)$ entre 5.7 e $7.3 \mathrm{~m} / \mathrm{min}$;

- Intervalo de tensão $\left(\xi_{2}\right)$ entre 26.5 e $29.5 \mathrm{~V}$.

$\mathrm{O}$ ponto central do $\mathrm{PCC}$ encontra-se na metade da região de trabalho, em $28 \mathrm{~V}$ e $6.5 \mathrm{~m} / \mathrm{min}$ de tensão e velocidade de alimentação do arame respectivamente. A Figura 1 apresenta a distribuição dos nove pontos de trabalho na região de estudo em relação às variáveis de entrada. Os valores correspondentes às variáveis codificadas em $\pm \sqrt{2}$ (testes do planejamento estrela) foram arredondados para uso na fonte de soldagem. A Tabela 2 apresenta a relação entre variáveis codificadas e variáveis de entrada nos pontos de trabalho utilizados, segundo a Figura 1 e a Tabela 1.

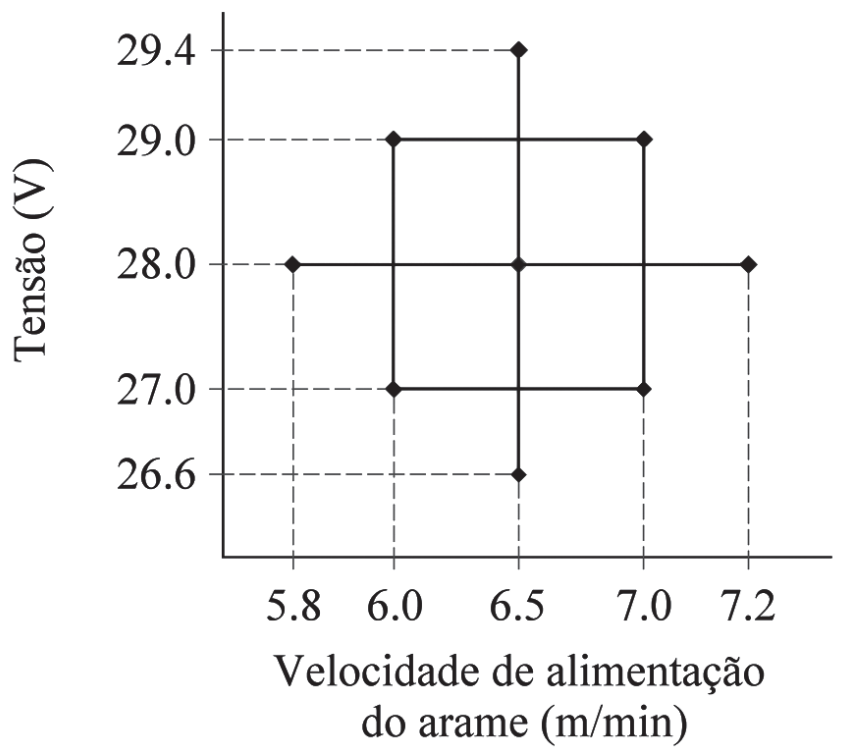

Figura 1. Planejamento experimental para as duas variáveis de entrada; velocidade de alimentação do arame $\left(\xi_{1}\right)$ e tensão

$\left(\xi_{2}\right)$
Tabela 2. Relação entre variáveis codificadas e variáveis de entrada

\begin{tabular}{|c|c|c|c|c|}
\hline \multirow{2}{*}{ Observação } & \multicolumn{2}{|c|}{$\begin{array}{c}\text { Variáveis } \\
\text { codificadas }\end{array}$} & \multicolumn{2}{c|}{ Variáveis de entrada } \\
\cline { 2 - 5 } & $x_{1}$ & $x_{2}$ & $\begin{array}{c}\text { Velocidade } \\
\text { de alimentação } \\
\left(\hat{\mathbf{i}}_{1}\right)(\mathrm{m} / \mathrm{min})\end{array}$ & $\begin{array}{c}\text { Tensão } \\
\left(\hat{\mathbf{1}}_{2}\right) \\
(\mathrm{V})\end{array}$ \\
\hline 1 & -1 & -1 & 6 & 27 \\
\hline 2 & 1 & -1 & 7 & 27 \\
\hline 3 & -1 & 1 & 6 & 29 \\
\hline 4 & 1 & 1 & 7 & 29 \\
\hline 5 & $-\sqrt{2}$ & 0 & 5.8 & 28 \\
\hline 6 & $\sqrt{2}$ & 0 & 7.2 & 26.6 \\
\hline 7 & 0 & $-\sqrt{2}$ & 6.5 & 29.4 \\
\hline 8 & 0 & $\sqrt{2}$ & 6.5 & 28 \\
\hline 9 & 0 & 0 & 6.5 & \\
\hline
\end{tabular}

\section{Medição de Parâmetros}

As respostas dos experimentos foram medidas usando técnicas de processamento de imagens digitais em sequências de fotografias da transferência metálica, adquiridas por meio de uma câmera de alta velocidade, e a técnica de perfilografia (descrita em trabalhos como Balsamo et al. [12]). Para o caso neste trabalho, o clássico arranjo de lente divergente-convergente, utilizado como expansor do feixe laser pela perfilografia, foi alterado para um arranjo de lente divergente e dois espelhos côncavos, como descrito em Lopera [13] e Lopera et al. [14]. A câmera utilizada é do tipo CMOS (DALSA, modelo DS-21-001M150) com filmagens feitas a uma taxa de 1000 quadros por segundo, com resolução espacial de 180x96 pixeis e 256 tons de cinza por um tempo de 6 segundos. A Figura 2 apresenta, como exemplo, uma sequência de imagens adquiridas durante os experimentos.

Com base na metodologia descrita em Lopera [13] e Lopera e Alfaro [15], para medir os parâmetros de interesse de um processo de transferência goticular, são analisadas sequências de 100 imagens. A frequência de destacamento é calculada pela contagem das gotas que são transferidas para a poça durante um intervalo de tempo. O tamanho das gotas é medido a partir das gotas que são transferidas para a poça neste mesmo período. Desta forma, após o processo de aquisição das imagens, a metodologia empregada pode ser descrita nos seguintes passos:

- Pré-processamento da imagem digital

- Limiarização das imagens

- Rotulação de objetos

- Medição do tamanho da gota

- Medição da frequência de destacamento 


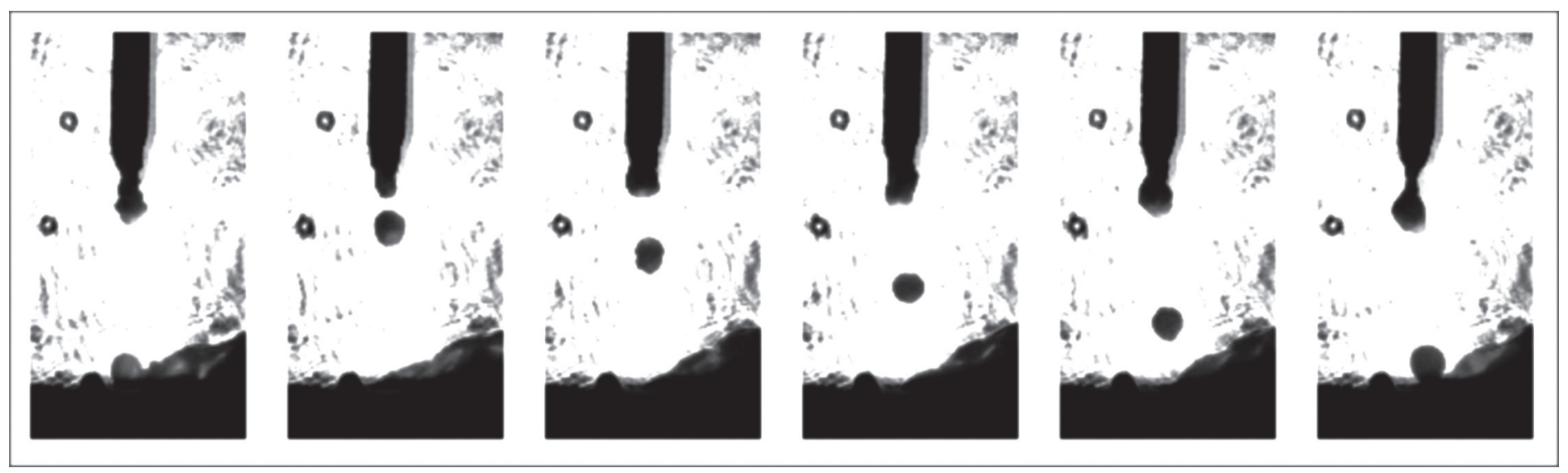

Figura 2. Sequência de imagens obtidas no modo de transferência goticular em 6ms de soldagem [13]

\subsection{Pré-processamento da imagem digital}

Apesar de apresentar um contraste favorável entre os objetos e o fundo, as imagens de perfilografia são caracterizadas pela presença constante de ruído gaussiano, causado principalmente pela distribuição da energia do laser e sua interação com partículas muito pequenas no ar ou nas lentes e vidros de proteção. Um ruído de outra natureza, mais evidente, aparece devido à sujeira nos vidros de proteção causada principalmente por respingos, como mostrado na Figura 3. A função principal do pré-processamento é melhorar a imagem, reduzindo ruídos, de forma a aumentar as chances de sucesso dos processos seguintes.

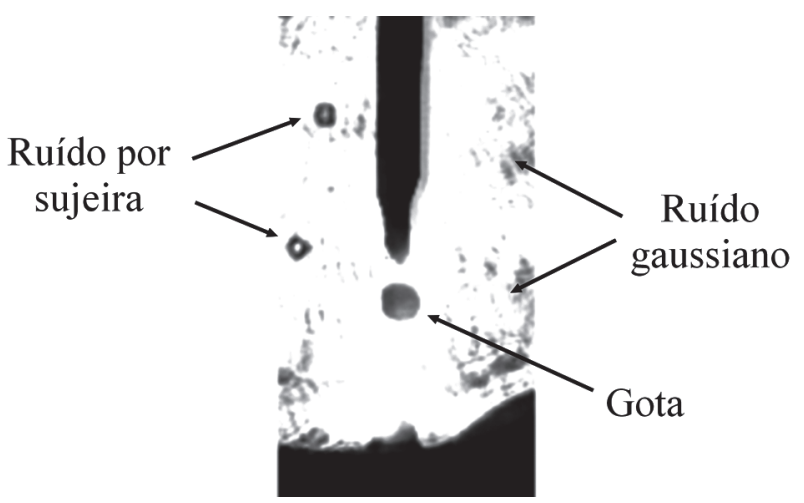

Figura 3. Ruído nas imagens adquiridas

Com base no trabalho de Maia [8], neste trabalho optou-se pela utilização de filtros espaciais de suavização para redução de ruído. Para isto, foram utilizados um filtro gaussiano linear e um filtro mediana não-linear, ambos construídos com máscaras (kernel) de tamanho $3 \times 3$. O filtro gaussiano tem como finalidade suavizar a imagem, ponderando o valor dos pixeis de acordo com os seus vizinhos. O filtro mediana é utilizado para eliminar pixeis isolados, retirando da imagem grandes áreas com ruído não-linear na forma de regiões compostas por cadeias de pixeis separados. A aplicação sequencial dos filtros sobre uma imagem pode ser vista na Figura 4.

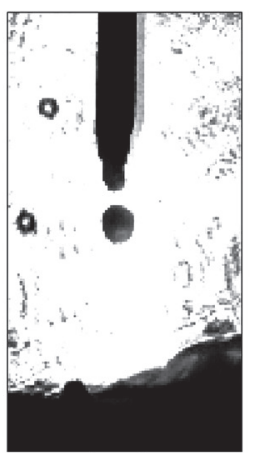

( a )

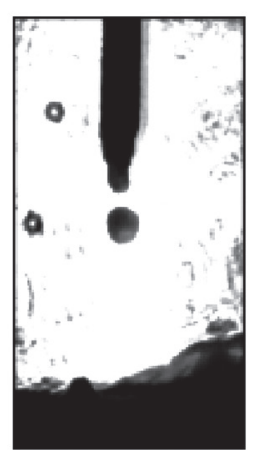

( b )

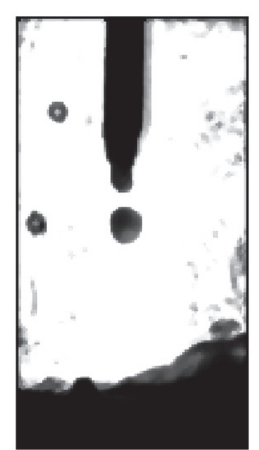

(c)
Figura 4. Aplicação dos filtros; (a) imagem original; (b) com o filtro gaussiano; (c) com o filtro mediana

\subsection{Limiarização das imagens}

O passo seguinte no processamento é dividir a imagem em partes ou objetos que a constituem, permitindo diferenciar estes objetos entre si e do fundo na imagem (neste caso os objetos são o arame, as gotas e a chapa). Este passo é conhecido comumente como segmentação. Neste trabalho, o primeiro estágio na segmentação das imagens é feito com a técnica de limiarização, que consiste em aplicar um limiar de tom de cinza $(T)$ à imagem ( 0 $\leq f(x, y) \leq 255)$, de tal forma que haja apenas dois tons, ou seja, transforma-se a imagem de tons de cinza em uma imagem binária em preto e branco $(g(x, y))$. Neste trabalho, utiliza-se somente um único limiar para cada imagem, o que permite denominar este estágio de limiarização também de binarização. A limiarização é aplicada segundo a seguinte relação:

$g(x, y)=\left\{\begin{array}{l}0 \operatorname{sef}(x, y)<T \\ 1 \operatorname{sef}(x, y) \geq T\end{array}\right.$

Neste trabalho, a limiarização é feita automaticamente, com base no método de Otsu [16], em duas etapas: uma global e outra de caráter dinâmico (de acordo com a classificação de Weska [17]). No caso da limiarização global, utiliza-se apenas a informação de intensidade da imagem (valor dos tons de cinza), e é 
realizada na imagem inteira. A limiarização dinâmica, além de utilizar a informação de intensidade, utiliza coordenadas espaciais para delimitar regiões dentro da imagem nas quais é realizada a limiarização.

Além de reduzir a interação do usuário com o processo, a limiarização automática tem importância em função da existência de variações no comprimento e na corrente do arco, além de outros fatores, que fazem com que a intensidade luminosa do arco se altere. Deste modo, os tons de cinza na imagem dos objetos afetados pelo arco (gotas e ponta do arame) se alteram também, bem como o ruído presente no fundo da imagem, o que exige um limiar diferente para cada imagem para garantir uma correta segmentação de objetos.

Na limiarização de caráter global, o interesse é eliminar ruído e identificar o principal objeto na imagem, o arame. A Figura 5 apresenta os resultados do processo de limiarização global em uma imagem adquirida da transferência metálica. Pode-se ver que, após a limiarização, algumas gotas na imagem (Figura 5 (b)) apresentam perda de informação relevante (de pixeis). Isto ocorre porque as gotas são envolvidas pelo arco, fazendo com que algumas regiões das imagens das mesmas fiquem comprometidas, apresentando tons de cinza com maior valor que o limiar e, por isso, eliminadas no processo de binarização.

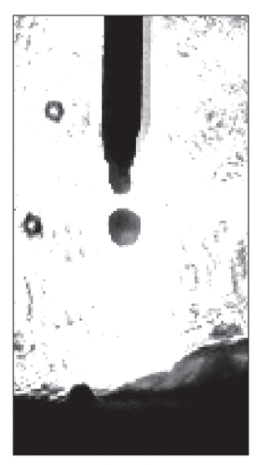

( a )

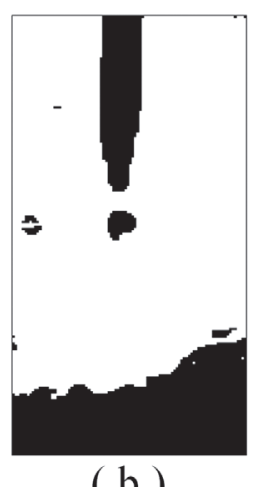

( b )
Figura 5. Limiarização da imagem com o método de Otsu; (a) imagem original; (b) imagem limiarizada

\subsection{Rotulação de objetos}

Uma vez que os objetos da imagem são separados do fundo, é necessário diferenciá-los entre si. Para isso, todos os pixeis que pertencem ao mesmo objeto serão identificados com o mesmo rótulo. Este processo é conhecido como rotulação e baseia-se principalmente nas características de conectividade entre pixeis de um mesmo objeto. No caso deste trabalho, a rotulação é feita percorrendo a imagem pixel por pixel, da esquerda para a direita e de cima para baixo. A avaliação de conectividade é feita com os 8 pixeis mais próximos (conectividade-8). Em alguns casos, depois de fazer o primeiro processo de rotulação, alguns objetos podem apresentar dois ou mais rótulos diferentes, o que torna necessário um processo de equalização de rótulos nos objetos; isto é feito percorrendo novamente a imagem e verificando que todos os vizinhos conexos ao pixel (em estudo) tenham o mesmo rótulo, se não, aplica-se o rótulo correspondente ao vizinho que tenha um valor diferente.

Deste modo, os objetos são completamente identificados, um a um, tornando possível contar e registrar as coordenadas de cada um de seus pixeis, permitindo definir o tamanho e a localização espacial de cada um. Nesta etapa, o ruído que não foi totalmente eliminado no processo de limiarização global é removido da imagem com uma regra de tamanho, comparando cada objeto com o tamanho da chapa. O ruído restante não supera 3\% da área da chapa. Pode-se verificar, na Figura 6, o uso da rotulação na eliminação de ruído.

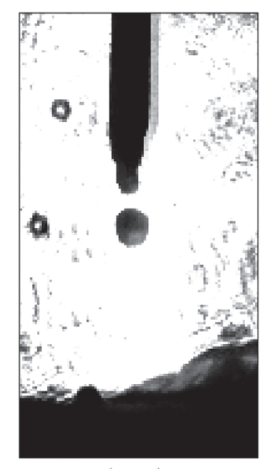

( a )

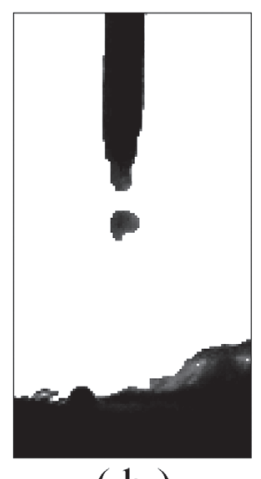

( b )
Figura 6. Eliminação total de ruído; (a) imagem original; (b) imagem sem ruído depois da rotulação

\subsection{Medição do Tamanho das Gotas}

Com a rotulação dos objetos são extraídas as coordenadas de linha e coluna () do último pixel (de cima para baixo) da ponta do arame e, também, as coordenadas do primeiro pixel da chapa. O primeiro pixel da chapa é tomado como o primeiro de cima para baixo e da esquerda para a direita (na chapa), local que não é influenciado pelo cordão. Desta forma, delimita-se a região do arco compreendida entre a ponta do arame e a chapa (como apresenta a Figura 7 (c) e (d)). Nesta área, novamente se utiliza o método de Otsu, finalizando-se a etapa de limiarização dinâmica (Figura 7 (e) e (f)).

Um processo de rotulação é feito novamente nesta região para obter informação (número e posições dos pixeis) dos objetos contidos nela. $\mathrm{O}$ ruído remanescente nesta limiarização pode ser eliminado facilmente com a regra de tamanho empregada na limiarização global. Geralmente a ponta da gota também aparece neste passo, mas ela é facilmente identificável (aparece na primeira linha da região) e não é considerada por não ser de importância neste passo. Uma primeira medição, chamada área da gota, é feita como sendo a soma dos pixeis que conformam a gota. Neste trabalho, a medição do tamanho é feita calculando o diâmetro das gotas com a relação apresentada na seguinte expressão:

$D=2\left(\sqrt{\frac{\text { área } d \text { gota }}{\pi}}\right)$

Outros trabalhos, como por exemplo, Figueiredo [18], medem o diâmetro da gota como o número de pixeis que ocupam 


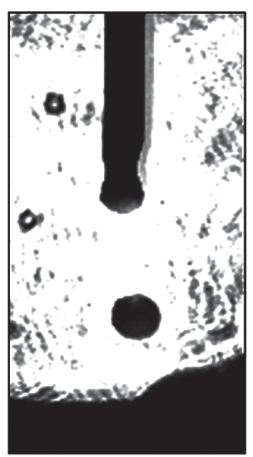

( a )

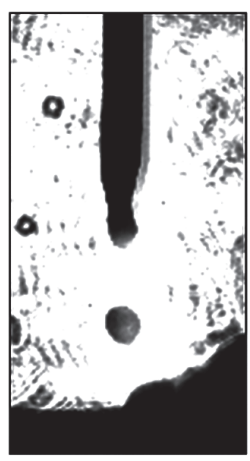

( b )

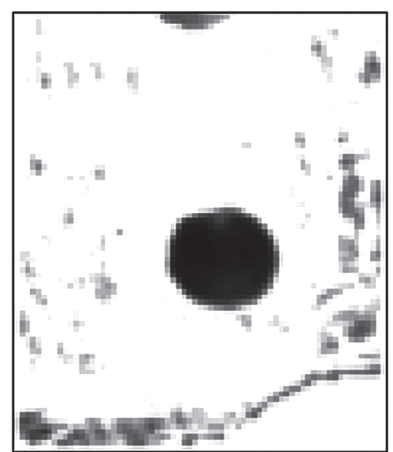

(c)

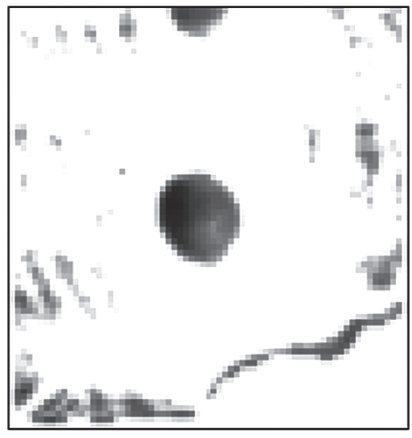

( d )

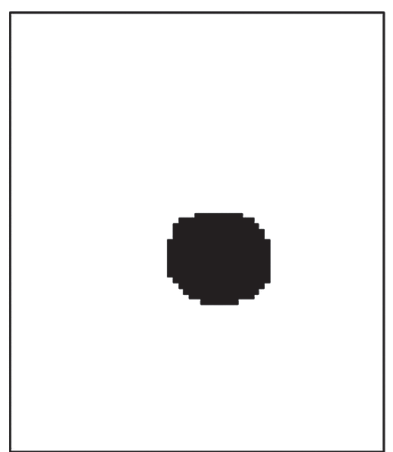

( e )

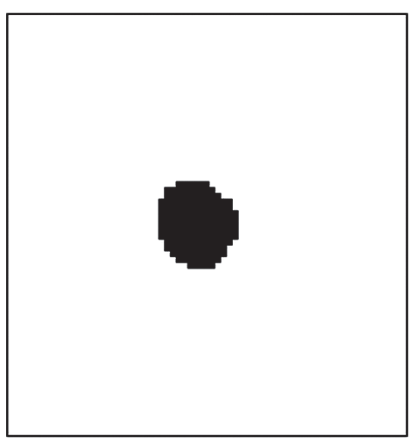

( f)
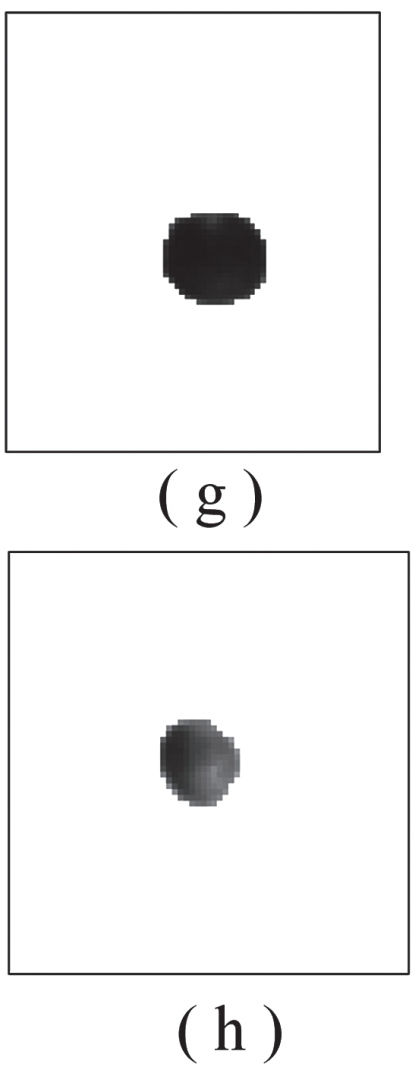

Figura 7. Processo para medir o tamanho da gota; (a) e (b) Imagens de transferência; (c) e (d) zona de influência do arco para suas respectivas imagens à esquerda; (e) e (f) limiarização dinâmica; (g) e (h) gota limpa para efeitos de comparação visual [13]
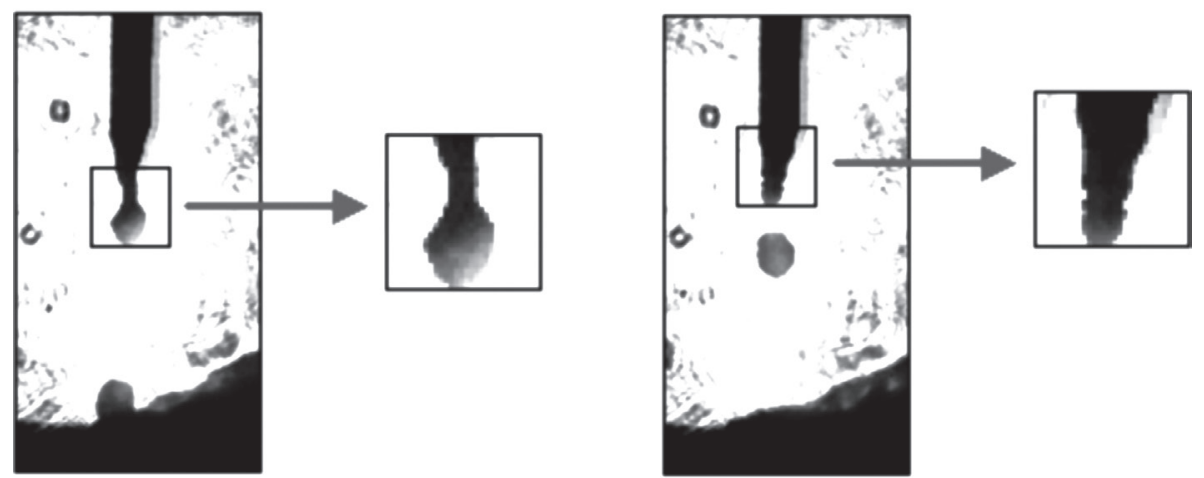

Figura 8. Região de analise para medir a frequência de destacamento, para duas imagens diferentes [13]

uma linha através do centro da gota, outros, como por exemplo, Weglowski, Huang e Zhang [19] utilizam a média aritmética do número de pixeis através da coluna e da linha que passam pelo centro da gota. A conversão de unidades (de pixeis para milímetros) pode ser feita de diferentes formas, por exemplo, com o uso de uma tela (referência) graduada com as unidades desejadas como explica Maia [8] em seu trabalho, com uma adequada calibração da câmera a partir da distancia focal das lentes utilizadas e a distancia do objeto à câmera como é documentado em Trucco e Verri [20], ou como no presente trabalho, com uma equivalência de unidades, sendo que o diâmetro do arame nas imagens é 16 pixeis e em milímetros é 1.2. Este método é menos robusto que os anteriores, mas encontram-se resultados aceitáveis, quan- do não se conta com as ferramentas nem os dados utilizados nos métodos mencionados anteriormente.

\subsection{Medição da Frequência de Destacamento}

Para medir a frequência de destacamento é necessário contar o número de gotas que são transferidas no processo durante um tempo fixo (neste caso $100 \mathrm{~ms}$ ). Assim, uma nova limiarização dinâmica ao redor da ponta do arame é feita, recuperando os possíveis pixeis perdidos no processo de limiarização global. Desta forma, segue-se quadro a quadro a ponta do arame em cada imagem procurando acompanhar o processo de empesco- 


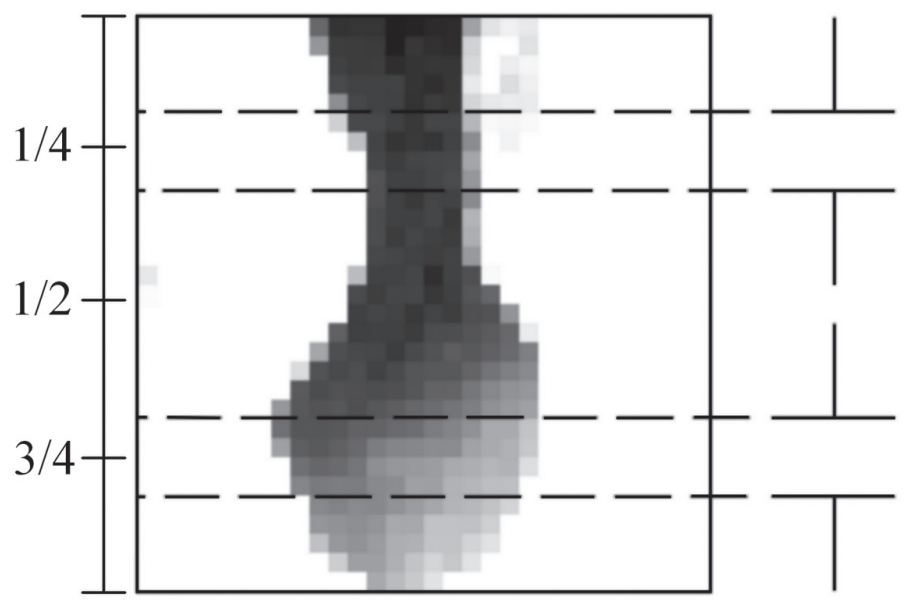

(a)

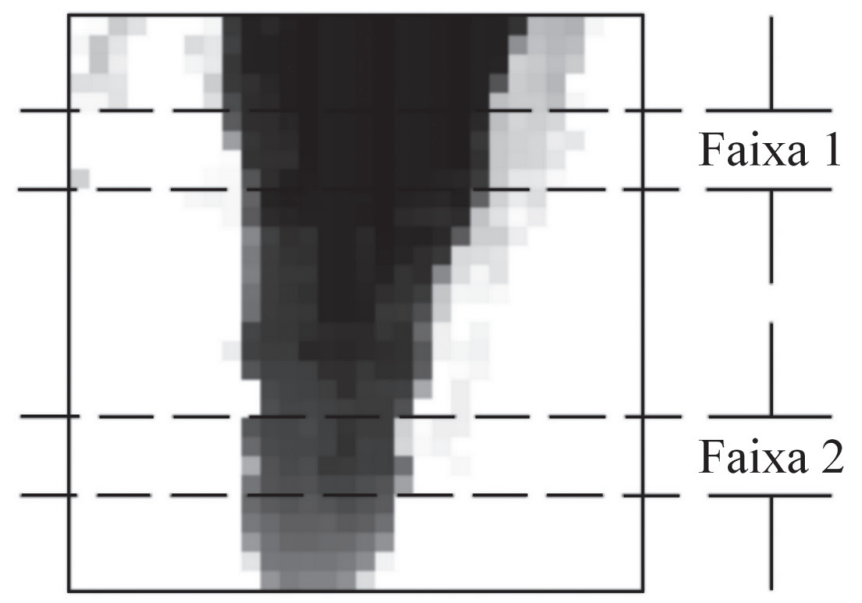

(b)

Figura 9. Faixas 1 e 2 no eixo vertical da região de analise. (a) Ponta do arame com a gota em formação; (b) ponta do arame depois do destacamento [13]

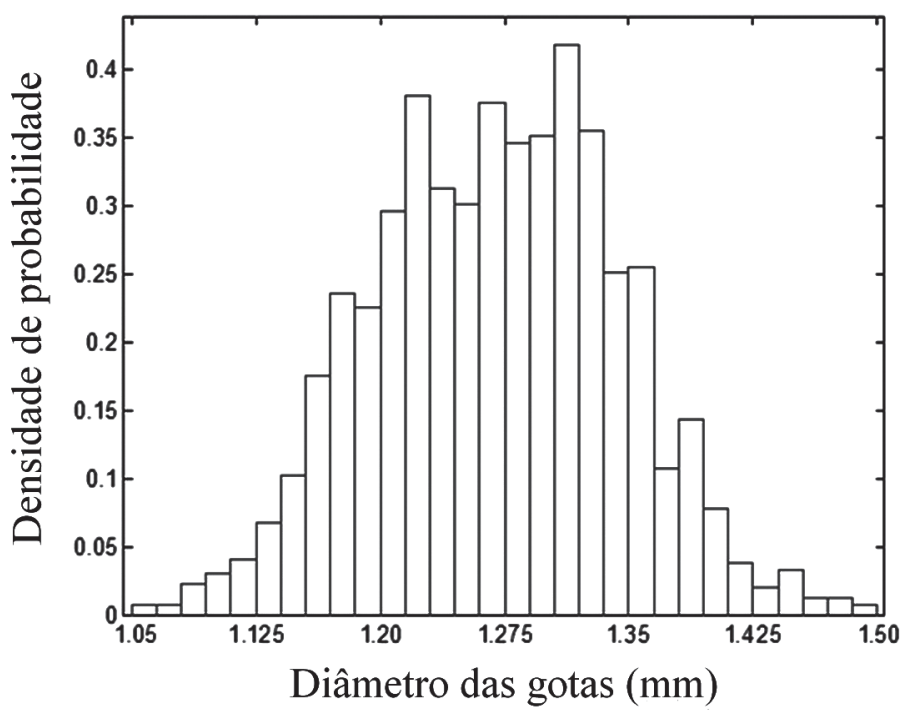

(a)

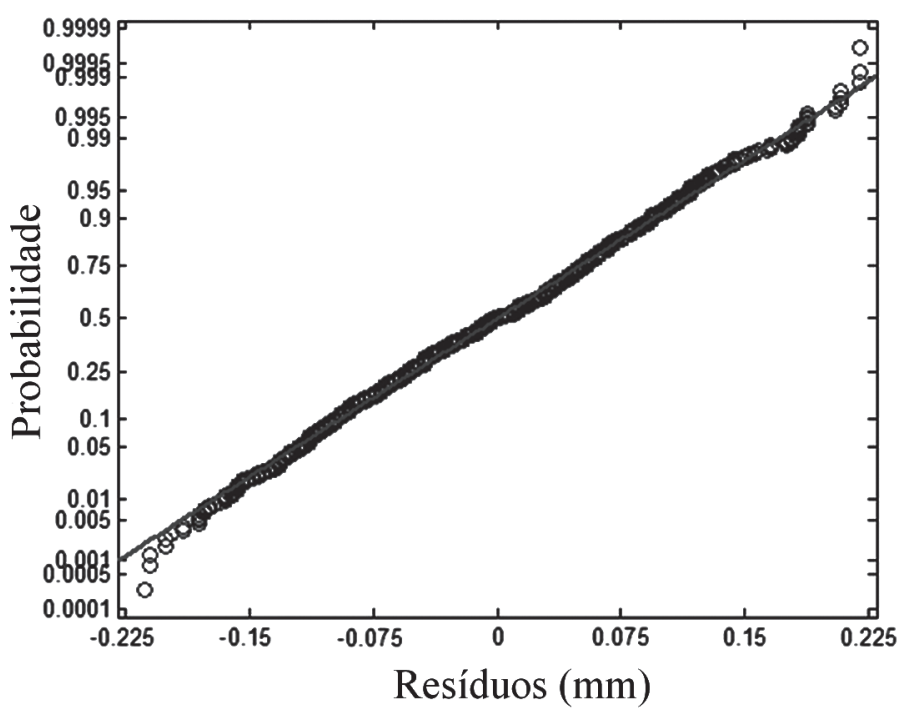

(b)

Figura 10. Diâmetro das gotas. (a) Densidade de Probabilidade VS Diâmetro de gotas; (b) Probabilidade VS Resíduos

çamento produzido pelo efeito Pinch na formação das gotas. Utilizando as coordenadas da ponta do arame proporcionadas pelo processo de rotulação, determina-se uma região de análise com comprimento igual ao dobro do diâmetro do arame, onde sua última linha coincide com a linha do último pixel do arame, como indica a Figura 8. Para saber se uma gota foi desprendida, são efetuadas medições da largura do pescoço e da gota sobre esta região.

Os estudos realizados sobre as imagens indicaram que existem duas faixas favoráveis a medições da largura do pescoço e da gota dentro da região de análise. Cada faixa é formada por 4 linhas de pixeis. A primeira, chamada de Faixa 1, está localizada a um quarto do início da região de análise no eixo vertical (Figura 9), utilizada para mensurar o pescoço. A segunda, chamada de Faixa 2, está localizada a três quartos da região e se utiliza para mensurar a gota. Neste caso, a largura denota a soma dos pixeis contidos nas linhas que formam cada faixa como indica a Figura 9.

Quando a gota está se formando e o pescoço se manifesta, o número de pixeis localizados na Faixa 1 é menor que o número de pixeis que está na Faixa 2. Depois do destacamento da gota até o aparecimento do pescoço, o resultado é oposto, como pode ser observado na Figura 9. A comparação das faixas e o seguimento do processo quadro por quadro indicam a frequência de destacamento das gotas no processo de soldagem.

\section{Resultados}

\subsection{Sistema de medição de parâmetros}

As Figuras 10 e 11 apresentam os gráficos de densidade de probabilidade e de probabilidade normal dos resíduos das me- 


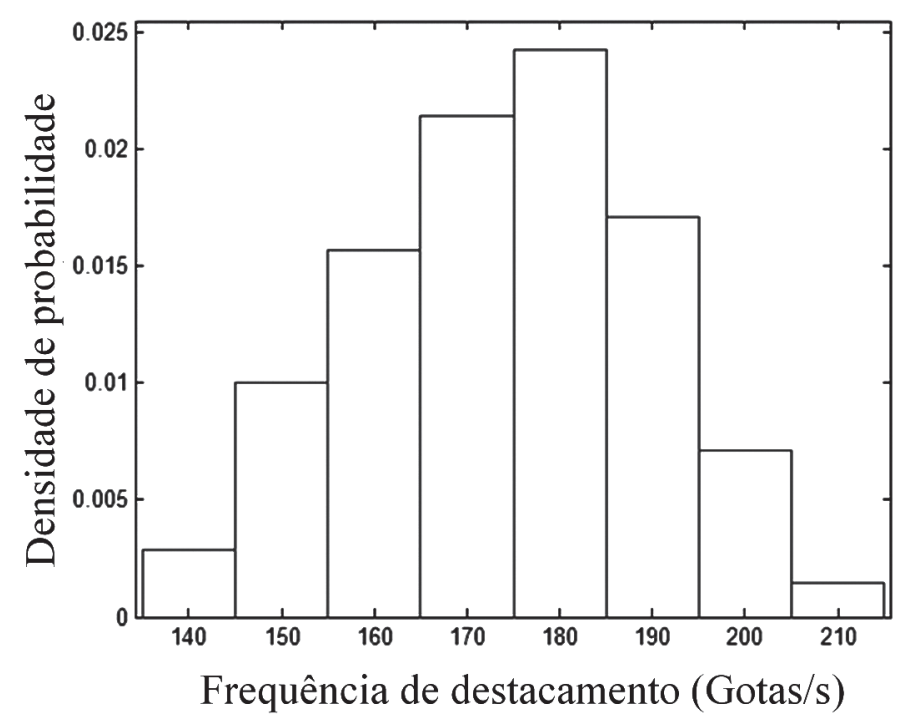

( a )

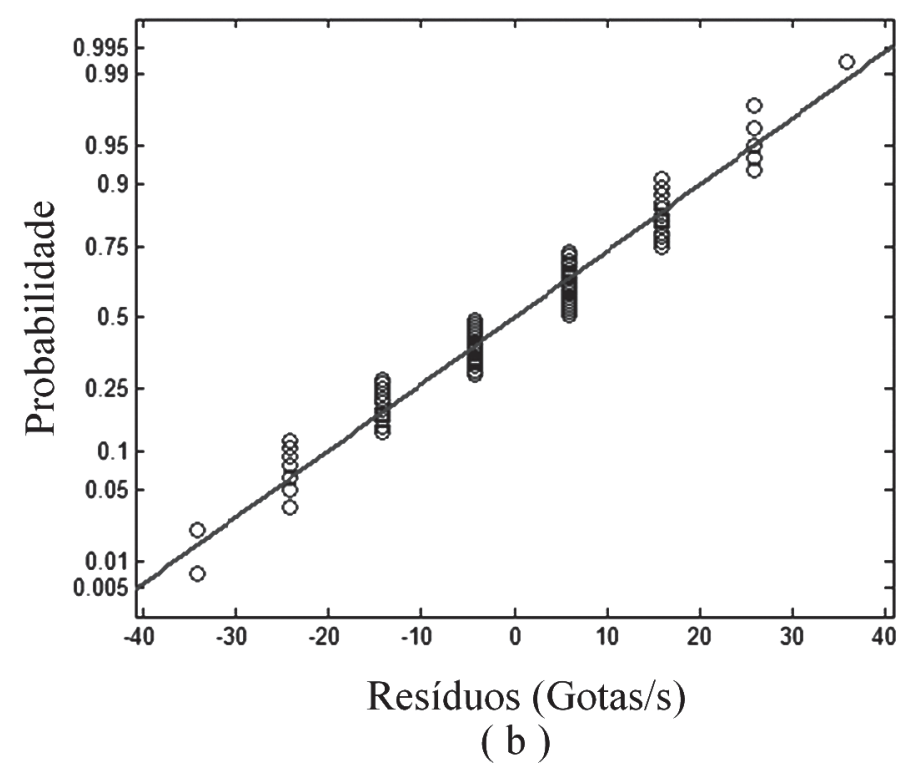

(b)

Figura 11. Frequência de destacamento. (a) Densidade de Probabilidade VS Frequência de destacamento; (b) Probabilidade VS Resíduos

dições do diâmetro e da frequência de destacamento das gotas respectivamente, no ponto de trabalho $27 \mathrm{~V}$ de tensão e $7 \mathrm{~m} /$ min de velocidade de alimentação do arame. Pode-se verificar nos gráficos que os valores têm uma tendência central e que indicam uma distribuição normal das medições. Estes comportamentos, encontrados também nos outros pontos de trabalho, são esperados por ser a transferência goticular projetada referenciada como a mais estável nos modos de transferência naturais na soldagem GMAW e sugerem um comportamento aceitável do sistema de medição.

A Tabela 3 apresenta os resultados da medição do diâmetro e da frequência de destacamento nos 9 pontos de trabalho, com as quatro repetições no ponto central $\left(x_{1}=0, x_{2}=0 ; \xi_{1}=6.5 \mathrm{~m} /\right.$ $\min , \xi_{2}=28 \mathrm{~V}$ ) que estabelece o planejamento experimental. Cada resultado é a média amostral de 5 medições diferentes no mesmo ponto de trabalho. No caso das medições da frequência de destacamento das gotas que foram medidas para um tempo de $100 \mathrm{~ms}$, os resultados foram multiplicados por 10 para ter-se um valor de frequência aproximado a um segundo.

Tabela 3. Resultados encontrados nas medições do planejamento experimental

\begin{tabular}{|c|c|c|c|c|}
\hline \multirow[b]{2}{*}{$\begin{array}{l}\text { Obser- } \\
\text {-vação }\end{array}$} & \multicolumn{2}{|c|}{ Variáveis de entrada } & \multicolumn{2}{|c|}{ Respostas } \\
\hline & $\begin{array}{l}\text { Velocidade de } \\
\text { alimentação } \\
\left(\xi_{1}\right)(\mathrm{m} / \mathrm{min})\end{array}$ & $\begin{array}{l}\text { Tensão } \\
\left(\xi_{2}\right)(V)\end{array}$ & $\begin{array}{c}\text { Diâmetro } \\
(\mathrm{mm})\end{array}$ & $\begin{array}{l}\text { Frequência de } \\
\text { destacamento } \\
\text { (Gotas/s) }\end{array}$ \\
\hline 1 & 6 & 27 & 1.370 & 123.34 \\
\hline 2 & 7 & 27 & 1.270 & 174.94 \\
\hline 3 & 6 & 29 & 1.313 & 124.40 \\
\hline 4 & 7 & 29 & 1.164 & 215.77 \\
\hline 5 & 5.8 & 28 & 1.340 & 116.5 \\
\hline 6 & 7.2 & 28 & 1.192 & 218.65 \\
\hline
\end{tabular}

\begin{tabular}{|c|c|c|c|c|}
\hline 7 & 6.5 & 26.6 & 1.303 & 142.51 \\
\hline 8 & 6.5 & 29.4 & 1.183 & 183.48 \\
\hline 9 & 6.5 & 28 & 1.270 & 158.28 \\
\hline 10 & 6.5 & 28 & 1.276 & 155.14 \\
\hline 11 & 6.5 & 28 & 1.272 & 156.00 \\
\hline 12 & 6.5 & 28 & 1.269 & 159.57 \\
\hline
\end{tabular}

De acordo com diferentes referências bibliográficas, ao aumentar a velocidade de alimentação de arame numa fonte de tipo tensão constante e manter os demais fatores de entrada constantes, a corrente do processo aumenta. No caso de aumentar a tensão e fixar os outros parâmetros de entrada, o comprimento do arco aumenta e o comprimento energizado do arame diminui pelo que o calor gerado por efeito Joule no arame diminui também, assim que, a corrente tende a aumentar e a taxa de consumo e mantida constante no processo. $\mathrm{O}$ aumento da corrente provoca um aumento na magnitude das forças de Lorentz, ocasionando que as gotas sejam formadas em menor tempo e assim sejam de menor tamanho e apresentem um aumento da frequência de destacamento. Este comportamento é apresentado nos resultados apresentados na Tabela 1, na qual as variáveis de entrada são a velocidade de alimentação do arame e a tensão de trabalho utilizadas na maquina de soldagem. Um fato importante é que o maior diâmetro de gota encontrado no ponto de trabalho $6 \mathrm{~m} /$ min, $27 \mathrm{~V}$ não superou mais de 1.14 vezes o diâmetro do eletrodo, o que concorda com o critério adotado do IIW.

\subsection{Modelagem}

Utilizando a Tabela 3 no vetor de resultados (Equação (3)) e com as Equações (1) e (5), o modelo de segunda ordem encontrado para o diâmetro das gotas em função da tensão e velocida- 
de de alimentação do arame é:

$\hat{y}_{D}=-95.99+5.26 \xi_{1}+7.75 \xi_{2}+0.18 \xi_{1}^{2}-0.11 \xi_{2}^{2}-0.32 \xi_{1} \xi_{2}$

, as unidades de medida deste modelo são pixeis, a mudança para milímetros é feita com a equivalência comentada com anterioridade. Para a frequência de destacamento, o modelo encontrado foi:

$\hat{y}_{F}=4737.27-679.78 \xi_{1}-198.5 \xi_{2}+15.0 \xi_{1}^{2}+1.46 \xi_{2}^{2}+19.88 \xi_{1} \xi_{2}$

A Tabela 4 apresenta a variância, o desvio padrão e a porcentagem do coeficiente de determinação múltipla ajustado (100. $R_{a d j}^{2}$ ) para cada modelo encontrado.

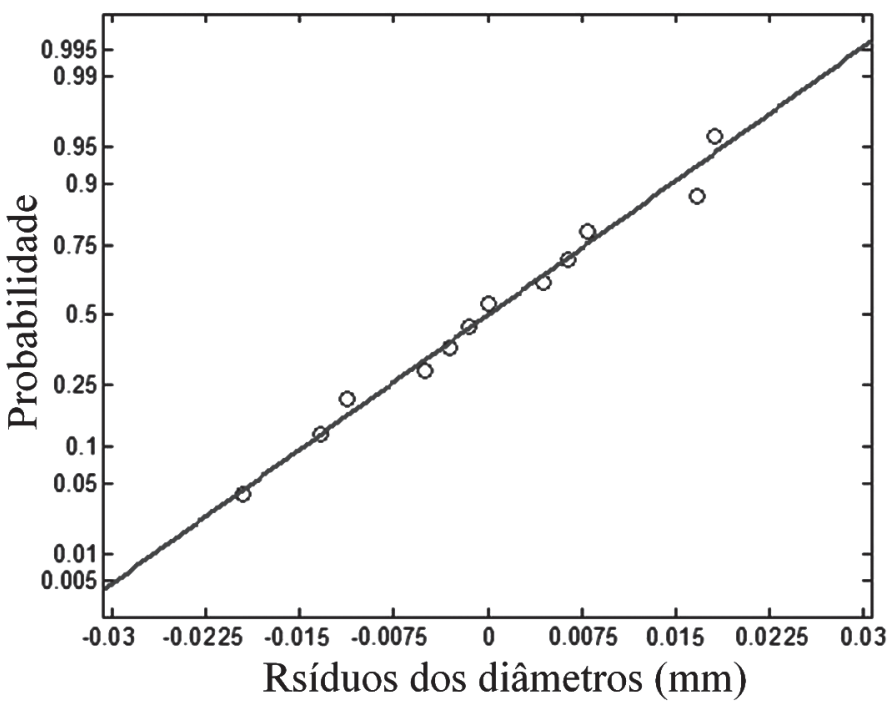

(a)

Figura 12. Gráficos de probabilidade normal dos resíduos dos modelos.

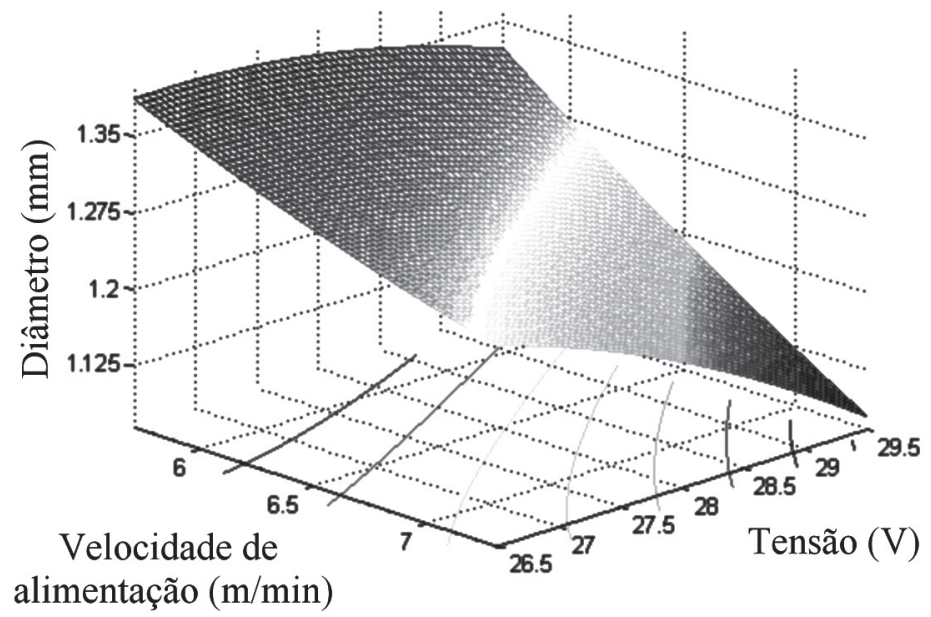

( a )
Tabela 4. Variância, desvio padrão e porcentagem do coeficiente de determinação múltipla ajustado

\begin{tabular}{|c|c|c|c|}
\hline Modelo & Variância & Desvio padrão & $\mathbf{\%} R_{a d j}^{2}$ \\
\hline $\begin{array}{c}\text { Tamanho } \\
\text { das gotas }\end{array}$ & $0.00025 \mathrm{~mm}^{2}$ & $0.01575 \mathrm{~mm}$ & $94.00 \%$ \\
\hline $\begin{array}{c}\text { Frequência de } \\
\text { destacamento }\end{array}$ & $18.21(\text { gotas } / \mathrm{s})^{2}$ & 4.27 gotas/s & $98.35 \%$ \\
\hline
\end{tabular}

Desta forma, pode-se observar que os modelos conseguem representar em $94 \%$ e $98.35 \%$ os resultados encontrados nos experimentos, considerados adequados para descrever o comportamento da transferência metálica nos processos. Como indicam Myers, Montgomery e Anderson-Cook [11], com os resultados reais dos experimentos $y_{i}$ e os valores entregados pelos modelos $\hat{y}_{i}$, outra abordagem eficaz de avaliar a adequação do modelo é calcular os resíduos $\left(e_{i}=y_{i}-\hat{y}_{i}\right)$ e dispor graficamente

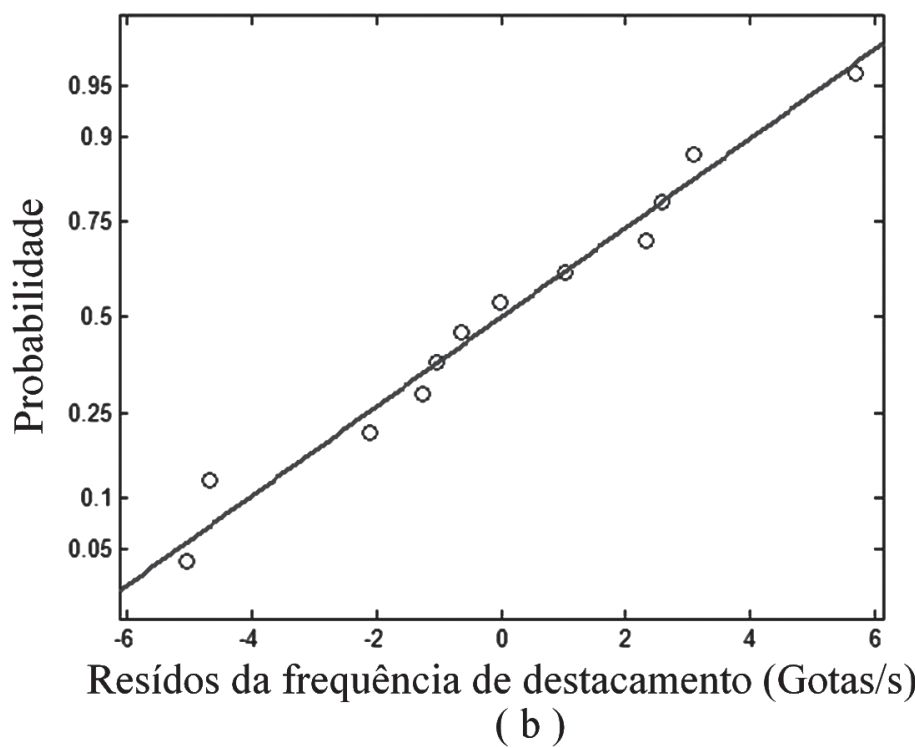

. (a) Para o diâmetro; (b) para a frequência de destacamento

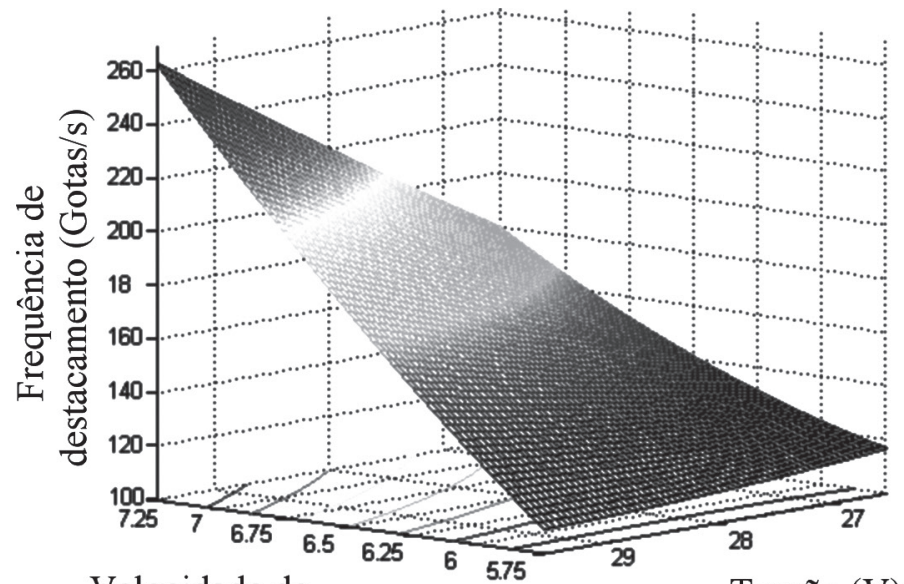

Velocidade de

Tensão (V) alimentação $(\mathrm{m} / \mathrm{min})$

( b )

Figura 13. Superfícies de resposta dos modelos. (a) Para o diâmetro; (b) para a frequência de destacamento 
algumas das quantidades calculadas. Examinam-se os gráficos para confirmar a opção do modelo ou para obter indicações de que o modelo não é o apropriado. Os gráficos a utilizar podem ser $y_{i}$ versus $\hat{y}_{i}, e_{i}$ versus $\hat{y}_{i}$, ou gráfico de probabilidade normal dos resíduos, entre outros. Neste caso, a Figura 12 apresenta os gráficos de probabilidade normal dos resíduos para cada modelo encontrado. Os gráficos mostram que os resíduos são distribuídos ao longo da linha reta que representa a distribuição normal, o que reforça a boa aproximação dos modelos aos processos de transferência.

Finalmente, a Figura 13 apresenta as superfícies de resposta encontradas para os modelos do tamanho e da frequência de destacamento das gotas. As superfícies de resposta permitem observar o comportamento advertido na Tabela 3 , à medida que os valores da tensão e da velocidade de alimentação do arame aumentam, o tamanho das gotas diminui e a frequência de destacamento aumenta, indicando o aumento da corrente em ambos os casos.

\section{Conclusões}

Este artigo apresenta uma metodologia capas de ser reproduzida para diferentes condições de trabalho e que permite medir e modelar o tamanho e a frequência de destacamento das gotas na transferência goticular projetada em processos de soldagem GMAW. A metodologia de superfície de resposta permitiu encontrar dois modelos de segunda ordem que representam o comportamento da transferência goticular projetada, para um processo de soldagem GMAW particular com arame MC, gás de proteção e distância bico de contato-peça constantes. Os gráficos de probabilidade normal dos resíduos, assim como as porcentagens dos coeficientes de determinação múltiplas ajustados, permitiram observar que os modelos estão representando de forma correta o diâmetro e a frequência de destacamento das gotas durante os processos de soldagem, validando em $94 \%$ e $98 \%$, respectivamente, os resultados encontrados nos experimentos. Pode-se concluir que os modelos foram validados como adequados para descrever a transferência.

Com respeito às técnicas de processamento de imagens digitais utilizadas para medir as respostas dos experimentos, pode-se dizer que a chave do seu êxito está em determinar corretamente as coordenadas da ponta do arame e da superfície da chapa, que não estejam sendo alcançadas pelo arco e, com elas, delimitar as regiões do arco e da ponta do arame, essenciais para realizar as medições de diâmetro e frequência de destacamento. Este ponto é corretamente atingido com o processo de rotulação dos objetos. Em referência à frequência de destacamento, pode-se dizer que os gráficos de densidade de probabilidade e de probabilidade normal dos resíduos, bem como a sua superfície de resposta, permitem concluir que o empescoçamento produzido pelo efeito Pinch na formação das gotas é um parâmetro adequado para rastrear a formação das mesmas e, desta forma, para calcular a frequência de destacamento.

\section{Referências Bibliográficas}

[1] SCOTTI, A.; PONOMAREV, V. Soldagem MIG/MAG: me- lhor entendimento, melhor desempenho. São Paulo, Brasil: Artliber Editora, 2008, 284 p.

[2] LYTTLE, K.A. Metal cored wires: where do they fit in your future?. Welding Journal, v. 75, p. 35-40, 1996.

[3] SUBRAMANIAM, S.; WHITE, D.; JONES, J.; LYONS, D. A Method for selection of process parameters in pulsed GMAW helps to efficiently develop welding procedures. Welding Journal, v.78, n.5, p.166-172, 1999.

[4] PRAVEEN, P.; KANG, M.J.; PRASAD, Y. Behaviour of metal transfer modes in pulse gas metal arc welding of aluminum. In: PROCEEDINGS OF 2006 ADVANCED MATERIALS PROCESSING TECHNOLOGIES CONFERENCE, 2006, Las Vegas, USA, p.1-8.

[5] MURRAY, P.E. Selecting parameters for GMAW using dimensional analysis. Welding Journal, v.81, n.7, p.125-131,2002. [6] CORREIA, D.; GONGALVES, C.; CUNHA, S.; FERRARESI, V. Comparison between genetic algorithms and response surface methodology in GMAW welding optimization. Journal of Materials Processing Technology, v. 160, p. 70-76, 2005.

[7] BENYOUNIS, K.Y.; OLABI, A.G. Optimization of different welding processes using statistical and numerical approaches - a reference guide. Advances in Engineering Software, v.39, p.483-496, 2008.

[8] MAIA, T.C. Utilização de técnicas de processamento digital de imagens no estudo de transferência metálica em soldagem a arco voltaico. 2001. 124p. Dissertação (Mestrado), Faculdade de Engenharia Elétrica, Universidade Federal de Uberlândia, Uberlândia, M-G, Brasil.

[9] SCOTTI, A.; PONOMAREV, V.; LUCAS, W. A Scientific application oriented classification for metal transfer modes in GMA welding. Journal of Materials Processing Technology, v. 212, p. 1406-1413, 2012.

[10] IORDACHESCU, D.; LUCAS, W.; PONOMAREV, V. Reviewing the "classification of metal transfer". IIW Doc., No. XII-1888-06, 2006.10 p.

[11] MYERS, R.H.; MONTGOMERY, D.C.; ANDERSONCOOK, C. Response surface methodology: process and product optimization using designed experiments. 3 ed. New Jersey, USA: John Wiley \& Sons, 2009, 680p.

[12] BÁLSAMO, P.S.; VILARINHO L.O.; VIELA, M.; SCOTTI, A. Development of an experimental technique for studying metal transfer in welding: synchronized shadowgraphy. International Journal for the Joining of Materials, v.12, n.1, p.1-12, 2000.

[13] LOPERA, J.E.P. Modelagem empírica da transferência goticular projetada em processos de soldagem GMAW baseada em técnicas de processamento de imagens digitais e superfícies de resposta. 2010. 136p. Dissertação (Mestrado), Faculdade de Tecnologia, Universidade de Brasília, Brasília, Brasil.

[14] LOPERA, J.E.P.; RAMOS, E. G.; CARVALHO, G. C.; ALFARO, S. Uso da técnica de "perfilografia" para visualização dos modos de transferência metálica no processo de soldagem GMAW usando uma câmera CMOS de alta velocidade. In: CONGRESSO BRASILEIRO DE ENGENHARIA DE FABRICAÇÃO, $6^{\circ}$, 2011, Caxias do Sul, RS, Brasil.

[15] LOPERA, J.E.P.; ALFARO, S. Response surface methodology to model the projected spray metal transfer in GMAW. 
In: $21^{\text {st }}$ BRAZILIAN CONGRESS OF MECHANICAL ENGINEERING, 2011, Natal, RN, Brazil.

[16] OTSU, N. A threshold selection method from gray-level histograms. IEEE Transactions on Systems, Man and Cybernetics, v.9, n.1, p.62-66, 1979.

[17] WESKA, J.S. A survey of thresholding selection techniques. Computer Graphics and Image Processing, v.5, p.382399, 1978.

[18] FIGUEIREDO, K.M. Mapeamento dos modos de transferência metálica na soldagem MIG de alumínio. 2000. 75p. Dissertação (Mestrado), Faculdade de Engenharia Mecânica, Universidade Federal de Uberlândia, Uberlândia, Brasil.

[19] WEGLOWSKI,M.; HUANG, Y.; ZHANG, Y. Effect of welding current on metal transfer in GMAW. Archives of Materials Science and Engineering, v.33 p.49-56, 2008.

[20] TRUCCO, E.; VERRI, A. Introductory techniques for 3-D computer vision. Upper Saddle River, NJ, USA: Prentice Hall, 1998, $343 \mathrm{p}$. 